Table 2. Clinical profile of patients with Tuberculosis

\begin{tabular}{|c|c|c|c|c|}
\hline \multicolumn{5}{|c|}{ Clinical profile of Tuberculosis cases } \\
\hline Clinical parameter & Adult lupus ( $\mathrm{n}=8, \%)$ & Pediatric lupus $(n=10, \%)$ & Myositis $(n=24, \%)$ & P (SLE Vs. IIM) \\
\hline Cases on high dose steroid" & $3(37.5)$ & $4(40.0)$ & $5(20.8)$ & 0.15 \\
\hline Disease duration <=1 year & $4(50)$ & $4(40)$ & $8(33.3)$ & 0.50 \\
\hline Pulmonary: Extra-pulmonary & 4:4 & 5:5 & $5: 7$ & 0.76 \\
\hline Tissue/Fluid diagnosis & $1(12.5)$ & $7(70)$ & $10(41.7)$ & 1.00 \\
\hline Active underlying disease & $4(50)$ & $7(70)$ & $12(50)$ & 0.54 \\
\hline Relapse of TB & $2^{*}(25)$ & 0 & $2(11.8)$ & 0.76 \\
\hline \multicolumn{5}{|l|}{ Resistant Tuberculosis } \\
\hline MDR suspect & 0 & 0 & 2 & 0.09 \\
\hline Pre-XDR & 0 & 0 & 1 & 1.00 \\
\hline Death & $1(12.5)$ & $1(12.5)$ & 0 & 0.09 \\
\hline
\end{tabular}

Disclosure of Interests:

Latika Gupta: None declared, Abhishek Zanwar: None declared, Rohit Aggarwal Grant/research support from: Pfizer, Genentech, BMS, Mallinckrodt, Consultant of: Pfizer, Genentech, BMS, Mallinckrodt, Bristol Myers-Squibb, octapharma, CSL Behring, AstraZeneca, Corbus, Kezar, Abbvie, Able Lawrence: None declared, Durga Misra: None declared, Vikas Agarwal: None declared, Ramnath Misra: None declared, Amita Aggarwal: None declared

DOI: 10.1136/annrheumdis-2020-eular.301

\section{AB0582 DIAGNOSING SYSTEMIC SCLEROSIS WITH PHOTOACOUSTIC AND HIGH-FREQUENCY ULTRASOUND IMAGING}

B. Kersten ${ }^{1}$, K. Daoudi ${ }^{2}$, C. H. M. Van den Ende ${ }^{1}$, F. Van den Hoogen ${ }^{1}$, C. De Korte $^{2}$, M. Vonk ${ }^{1}{ }^{1}$ Radboud University Medical Center, Rheumatology, Nijmegen, Netherlands; ${ }^{2}$ Radboud University Medical Center, Radiology and Nuclear Medicine, Nijmegen, Netherlands

Background: Vasculopathy is already evident in early systemic sclerosis (SSc); Raynaud's phenomenon and typical nailfoldcapillaroscopic findings are part of the criteria of very early diagnosis of SSc (VEDOSs) (1). As not all early SSc patients have alterations in their nailfoldcapillaries, there is need for other diagnostic tools. Photoacoustics(PA) and high-frequency ultrasound (HFUS) might be able to fulfill this need (2). The former can measure the oxygen saturation of hemoglobin by using short pulsed laser light while the latter can provide high-resolution images that allow measuring skin thickening distal from DIP joint, which could be used to determine skin involvement early.

Objectives: We hypothesize that photoacoustics and high-frequency ultrasound can distinguish (early) SSc patients from individuals with primary Raynaud's phenomenon (PR) by measuring the oxygenation (by PA) of the fingertip and skin thickening (by HFUS).

Methods: In our cross-sectional study, we compared measurements of the third finger in (early)SSc patients with individuals with PR and healthy volunteers. Smoking and beta-blockage were exclusion criteria. The level of oxygenation (by PA) and skin thickness (by HFUS) were compared between groups. Nailfoldcapillaroscopy was performed on all subjects and analyzed for the pattern.

Results: Thirty-one adult subjects participated in this study: twelve patients with SSc, 5 patients with early SSc, 5 volunteers with PR and 9 healthy controls.

We found a significant difference in median (IQR) oxygen saturation between earlySSc patients $75.9 \%$ (IQR 75.1\%-86.6\%) and subjects with PR 94.1\% (IQR $93.1 \%-94.5 \%)(p=0.0002)$ using the Wilcoxon rank-sum test (figure 1).

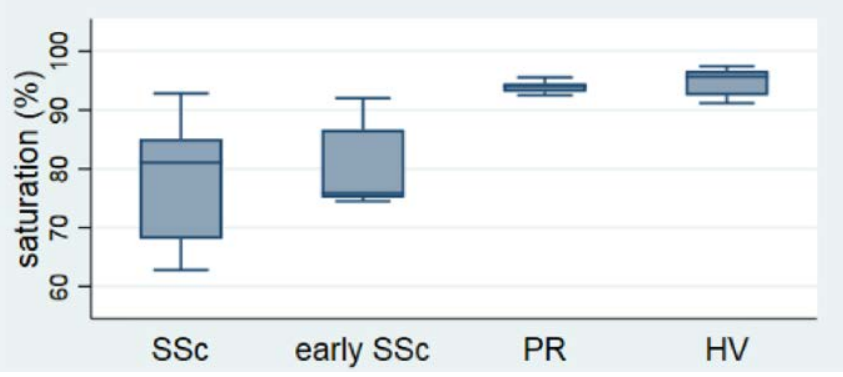

Figure 1. Boxplot of saturation (\%) per group.

Measurements of skin thickening also showed a significant difference in early SSc patients compared to subjects with PR, respectively $0.5 \mathrm{~mm}$ (IQR $0.4 \mathrm{~mm}-0.5 \mathrm{~mm}$ ) vs. $0.3 \mathrm{~mm}$ (IQR $0.3 \mathrm{~mm}-0.3 \mathrm{~mm}$ ), $\mathrm{P}=0.0002$ (figure 2).

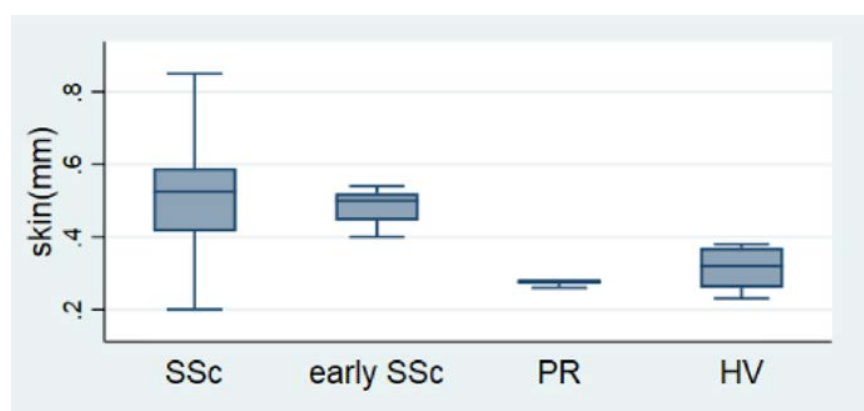

Figure 2. Boxplot of skin thickness ( $\mathrm{mm})$ per group.

Conclusion: Our results demonstrate that photoacoustic and high-frequency ultrasound can distinguish between (early)SSc and PR in both oxygenation saturation and skin thickening. In a larger prognostic study we want to determine the value of photoacoustic and high frequency ultrasound in diagnosing earlySSc.

References:

[1] Minier T, Guiducci S, Bellando-Randone S, Bruni C, Lepri G, Czirjak L, et al. Preliminary analysis of the very early diagnosis of systemic sclerosis (VEDOSS) EUSTAR multicentre study: evidence for puffy fingers as a pivotal sign for suspicion of systemic sclerosis. Annals of the rheumatic diseases. 2014;73(12):2087-93

[2] Wang LV, Yao J. A practical guide to photoacoustic tomography in the life sciences. Nature methods. 2016;13(8):627-38

Disclosure of Interests: Brigit Kersten: None declared, Khalid Daoudi: None declared, C.H.M. van den Ende: None declared, FHJ van den Hoogen Consultant of: AbbVie, Actelion, Biogen, BMS, Celltrion, Corbus, Eli-Lilly, Mundipharma, Pfizer, Sanofi-Genzyme, Speakers bureau: Amgen, Boehringer-Ingelheim, Novartis, CL de Korte: None declared, Madelon Vonk Grant/research support from: Janssen and Ferrer, Consultant of: Boehringer Ingelheim, Janssen and GSK, Speakers bureau: Boehringer Ingelheim, BMS and Roche DOI: 10.1136/annrheumdis-2020-eular.1388

\section{AB0583 COMPARISON OF THE RITUXIMAB (RTM) IN MONOTHERAPY REGIMEN AND CYCLOPHOSPHOMIDE (CYP) EFFICACY AND SAFETY IN SYSTEMIC SCLEROSIS (SSC) WITH INTERSTITIAL LUNG DISEASE (ILD)}

O. Koneva ${ }^{1}$, L. Ananieva ${ }^{1}$, L. Garzanova ${ }^{1}$, O. Desinova ${ }^{1}$, O. Ovsyannikova ${ }^{1}$, M. Starovoytova ${ }^{1} .{ }^{1}$ V.A. Nasonova Research Institute of Rheumatology, Moscow, Russian Federation

Background: CyP is considered as a drug of choice for the treatment of ILD in the patients with SSc. However, the use of CyP leads to rather limited and transient improvement of the pulmonary fibrosis. RTM is considered as a promising therapeutic agent for treatment of ILD in the patients with SSc. However, the limited number of RTM-treated patients, considerably different dose regimens, cumulative doses, and observation periods does not allow univocal conclusions on RTM efficacy or definitive recommendations on RTM use in the patients with SSc.

Objectives: To compare the impact of CyP and RTM a single-agent therapy on SSc clinical manifestation and activity, and the safety of these agents in the open-label prospective non-randomized study.

Methods: 71 patients with the confirmed SSc diagnosis and ILD evidence based on multispiral computed tomography findings were enrolled into the study. All patients received low-dose and moderate-dose glucocorticoids regimens. Group A $(n=35)$ received RTM as a single therapy agent over the follow-up period $13.3 \pm 2.3$ months in a total dose $1.35 \pm 0,5 \mathrm{~g}$ (the patient's average age was $45.0 \pm 15$ years, with female proportion $80 \%$; SSc duration $6.3 \pm 2.3$ years; diffused/localized forms 1.3/1). Group B ( $n=36$ ) received parenteral CyP for $12 \pm 6$ months at total dose $10.6 \pm 5 \mathrm{~g}$ (the average age $47 \pm 12$ years, females $92 \%$, SSc duration $5.0 \pm 4.8$ years, diffused/localized forms $1.6 / 1$ ). The age, gender proportion, SSc form and SSc duration, FVC, were similar in the both groups. The time courses of FVC, modified skin count (mRss, points), activity index (EScSG, points) were assessed in the study.

Results: The glucocorticoids starting dose that patients received at the time of inclusion in the study was significantly higher in group B compared to group A $(p=0.03)$. Only after a year of CyP therapy, the dose of glucocorticoids was reduced to the starting dose in group $A$. 
In Groups A and B the therapy was associated with significant decrease in mRss ( $p=0.02$ and 0.009 , respectively) and EScSG ( $p=0.00017$ and 0.000165 , respectively).

Evaluation of FVC time course in Groups A and B revealed significant FVC increase ( $p=0.002$ and 0.034 , respectively), with median increment about $5 \%$. The $10 \%$ FVC increase and decrease was similar in both groups.

The therapy was better tolerated in RTM-treated group: during RTM therapy adverse reactions emerged in significantly lower proportion of the patients (4/11\%) compared with CyP-treated group (19/53\%), $p=0,0000$

\begin{tabular}{lcc}
\hline Parameters & Group A & Group B \\
\hline Activity Index 1 & $2.8 \pm 1.4^{\star}$ & $3.2 \pm 1.9^{*}$ \\
$M \pm S D$ & & \\
Activity Index 2 & $1.4 \pm 1.2^{*}$ & $1.6 \pm 1.3^{*}$ \\
$M \pm S D$ & $11.5 \pm 9.5^{*}$ & \\
Skin count 1 & & $11.0 \pm 9.3^{*}$ \\
$M \pm S D$ & $8.2 \pm 6.2^{*}$ & \\
Skin count 2 & & $7.2 \pm 5.6^{*}$ \\
$M \pm S D$ & $78.7 \pm 20.0^{*}$ & \\
FVC $1 M \pm S D$ & $84.2 \pm 20.0^{*}$ & $76 \pm 20.3^{*}$ \\
FVC $2 M \pm S D$ & 5.3 & $82.7 \pm 22.5^{*}$ \\
$\Delta$ FVC $\%$ & {$[0.8 ; 11.1]$} & 5.7 \\
& $9 / 26$ & {$[0 ; 11.2]$} \\
FVC increment by $\geq 10 \%, \mathrm{n} / \%$ & $2 / 5.7$ & $14 / 31$ \\
FVC decrement by $\geq 10 \% \mathrm{n} / \%$ & $11.6 \pm 4.7$ & $2 / 4.4$ \\
Dose of glucocorticoids $1, \mathrm{mg}$ & $15.3 \pm 8.5^{\star}$ & $10.4 \pm 4.6$ \\
Dose of glucocorticoids $2, \mathrm{mg}$ & $2.9 \pm 5.4^{\star}$ \\
\hline N & & \\
\hline
\end{tabular}

Notes: in Parameters column 1 = before treatment, 2 = after treatment; $\mathrm{M} \pm \mathrm{SD}=$ mean value and standard deviation; ${ }^{*}=$ significant difference between the vales measured before and after the treatment

Conclusion: Both agents effectively alleviated skin induration and EScSG, and significantly improved FVC. However, the glucocorticoids doses that needed to be used during anti-B cell therapy were significantly lower compared to CyP treated patients. The RTM single therapy was better tolerated compared to CyP. The study findings substantiate potential use a RTM single therapy both as a first-line agent for ILD treatment in the patients with SSc, and in the event of CyP inefficacy of poor tolerability.

Disclosure of Interests: None declared

DOI: 10.1136/annrheumdis-2020-eular.4267

\section{AB0584 DOES ANTI-ACID TREATMENT INFLUENCE DISEASE PROGRESSION IN SYSTEMIC SCLEROSIS INTERSTITIAL LUNG DISEASE (SSC-ILD)? DATA FROM THE GERMAN SSC-NETWORK}

M. Kreuter ${ }^{1}$, F. Bonella ${ }^{2}$, G. Riemekasten ${ }^{3}$, U. Müller-Ladner ${ }^{4}$, J. Henes ${ }^{5}$, E. Siegert ${ }^{6}$, C. Guenther ${ }^{7}$, I. Koetter ${ }^{8}$, N. Blank ${ }^{9}$, C. Pfeiffer ${ }^{10}$, M. Schmalzing ${ }^{11}$, G. Zeidler ${ }^{12}$, P. Korsten ${ }^{13}$, L. Susok ${ }^{14}$, A. Juche ${ }^{15}$, M. Worm ${ }^{16}$, I. Jandova ${ }^{17}$, J. Ehrchen ${ }^{18}$, C. Sunderkoetter ${ }^{19}$, G. Keyszer ${ }^{20}$, A. Ramming ${ }^{21}$, T. Schmeiser ${ }^{22}$, A. Kreuter ${ }^{23}$, K. Kuhr ${ }^{24}$, H. M. Lorenz ${ }^{25}$, P. Moinzadeh ${ }^{26}$, N. Hunzelmann ${ }^{27}$. ${ }^{1}$ University Hospital Heidelberg, Center for Interstitial and Rare Lung Diseases, Thoraxclinic, Heidelberg, Germany; ${ }^{2}$ Ruhrlandclinic University Hospital Essen, Rheumatology, Essen, Germany; ${ }^{3}$ University Hospital Schleswig-Holstein, Rheumatology, Luebeck, Germany; ${ }^{4}$ Kerckhoff Clinic Bad Nauheim, Rheumatology, Bad Nauheim, Germany; ${ }^{5}$ University Hospital Tuebingen, Rheumatology, Tuebingen, Germany; ${ }^{6}$ Charite University Hospital Berlin, Rheumatologie, Berlin, Germany; ${ }^{7}$ University Hospital Carl Gustav Carus Dresden, Dermatology, Dresden, Germany; ${ }^{8}$ Asklepios Clinic Hamburg Altona, Rheumatology, Hamburg, Germany; ${ }^{9}$ University Hospital Heidelberg, Rheumatology, Heidelberg, Germany; ${ }^{10}$ University Medical Center UIm, Dermatology, Ulm, Germany; ${ }^{11}$ University Hospital Wuerzburg, Rheumatology, Wuerzburg, Germany; ${ }^{12}$ Johanniter Hospital Treuenbrietzen, Rheumatology, Treuenbrietzen, Germany; ${ }^{13}$ University Hospital Goettingen, Rheumatology, Goettingen, Germany; ${ }^{14}$ St. Josef Hospital Bochum, Dermatology, Bochum, Germany; ${ }^{15}$ Immanuel Hospital Berlin Buch, Rheumatology, Berlin, Germany; ${ }^{16}$ Charite University Hospital Berlin, Dermatology, Berlin, Germany; ${ }^{17}$ University Hospital Freiburg, Rheumatology, Freiburg, Germany; ${ }^{18}$ University Hospital Muenster, Dermatology, Muenster, Germany; ${ }^{19}$ University Hospital Halle, Dermatology, Halle, Germany; ${ }^{20}$ University Hospital Halle, Rheumatology, Halle, Germany;
${ }^{21}$ University Hospital Erlangen, Rheumatology, Erlangen, Germany;

${ }^{22}$ Hospital St. Josef Wuppertal, Rheumatology, Wuppertal, Germany

${ }^{23}$ HELIOS St. Elisabeth Clinic Oberhausen, Dermatology, Oberhausen, Germany; ${ }^{24}$ Univerity of Cologne, IMSB, Köln, Germany; ${ }^{9}$ University Hospital Heidelberg, Rheumatology, Heidelberg, Germany; ${ }^{26}$ University Hospital Cologne, Dermatology, Cologne, Germany; ${ }^{26}$ University Hospital Cologne, Dermatology, Cologne, Germany

Background: Gastroesophageal reflux (GER) is common in SSc and thus treatment with anti-acid therapy (AAT) is frequent. An association between GER and the development / progression of SSc-ILD has been hypothesized. However, outcomes of AAT on disease progression in SSc-ILD has only sparsely been studied.

\section{Objectives:}

Methods: The German Network for Systemic Scleroderma (DNSS), which includes SSc pts. prospectively, was analyzed for SSc-ILD. Those without progression at ILD $1^{\text {st }}$ diagnosis were categorized in AAT vs. no-AAT users and disease outcome was assessed.

Results: SSc-ILD was reported in 1165 (28.2\%) out of 4131 pts. 712 of SSc-ILD pts had no disease progression at ILD $1^{\text {st }}$ diagnosis. 567 used AAT while 145 did not. Baseline characteristics were similar between groups with regards to age (mean 54.7 years), BMI, time since SSc diagnosis and immunosuppressant use. Significant differences in no-AAT vs. AAT were found for gender (male 18\% vs. $25 \%, p=0.05)$, SSc subtype ( $p=0.002$, diffuse more common in AAT), lung function (DLCO $66 \%$ vs. $58 \%$, $p=0.001$; FVC $86 \%$ vs. $77 \%, p=0.001$ ), mRSS (8 vs. $11.5, p<0.01)$, esophageal involvement (32\% vs. $56 \%, p<0.01)$ and steroid use (30\% vs. $43 \%, p=0.005)$. While mortality did not differ between groups $(3.9 \%, p=$ 0.59), disease progression was more common in the AAT group than in no-AAT users $(24.5 \%$ vs. $13 \%, p=0.03)$. Furthermore, there was a significant difference in decline of $F V C \geq 10 \%$ with $30 \%$ in the AAT compared to $14 \%$ in no-AAT ( $p=0.018$ ); a decline in DLCO $\geq 15 \%$ was more common in the AAT group by trend ( $23 \%$ vs $14 \%, p=0.087$ ).

Conclusion: While results may have partially been biased by differences in baseline characteristics, this current analysis disfavors the approach of AAT use for SSc-ILD.

Disclosure of Interests: Michael Kreuter Grant/research support from: Roche, Boehringer, Consultant of: Roche, Boehringer, Speakers bureau: Boehringer, Roche, Francesco Bonella Grant/research support from: Boehringer, Consultant of: Boehringer, Roche, Bristol MS, Galapagos, Speakers bureau: Boehringer Roche, Gabriela Riemekasten Consultant of: Cell Trend $\mathrm{GmbH}$, Janssen, Actelion, Boehringer Ingelheim, Speakers bureau: Actelion, Novartis, Janssen, Roche, GlaxoSmithKline, Boehringer Ingelheim, Pfizer, Ulf Müller-Ladner Speakers bureau: Biogen, Jörg Henes Grant/research support from: Novartis, Roche-Chugai, Consultant of: Novartis, Roche, Celgene, Pfizer, Abbvie, Sanofi, Boehringer-Ingelheim, Elise Siegert Grant/research support from: Actelion, Consultant of: AEC, Speakers bureau: NA, Claudia Guenther: None declared, Ina Koetter Grant/research support from: Novartis, Roche, Speakers bureau: Abbvie, Actelion, Celgene, MSD, UCB, Sanofi, Lilly, Pfizer, Novartis, Chugai, Roche Boehringer, Norbert Blank Speakers bureau: Actelion, Roche, Boehringer, Pfizer, Chugai, Christiane Pfeiffer: None declared, Marc Schmalzing: None declared, Gabriele Zeidler: None declared, PETER KORSTEN Grant/research support from: Novartis, Juarms GmbH, Consultant of: Abbvie, Pfizer, Lilly, BMS, Speak ers bureau: Abbvie, Pfizer, chugai, BMS, Lilly, Sanofi aventis, Laura Susok: None declared, Aaron Juche: None declared, Margitta Worm Consultant of: Mylan Gemany, Bencard Allergie, BBV Technologies S.A., Novartis, Biotest, Sanofi, Aimmune Therapies, Regeneron, Speakers bureau: ALK-Abello, Novartis, Sanofi, Biotest, Mylan, Actelion, HAL Allergie, Aimmune Bencard Allergie, Ilona Jandova: None declared, Jan Ehrchen: None declared, Cord Sunderkoetter: None declared, Gernot Keyszer: None declared, Andreas Ramming Grant/ research support from: Pfizer, Novartis, Consultant of: Boehringer Ingelheim, Novartis, Gilead, Pfizer, Speakers bureau: Boehringer Ingelheim, Roche, Janssen, Tim Schmeiser Speakers bureau: Actelion, UCB, Pfizer, Alexander Kreuter Speakers bureau: Sanofi, Abbvie, Merck Sharp\&Dohme, Boehringer, Kathrin Kuhr: None declared, Hanns-Martin Lorenz Grant/research support from: Consultancy and/or speaker fees and/or travel reimbursements: Abbvie, MSD, BMS, Pfizer, Celgene, Medac, GSK, Roche, Chugai, Novartis, UCB, Janssen-Cilag, Astra-Zeneca, Lilly. Scientific support and/or educational seminars and/or clinical studies: Abbvie, MSD, BMS, Pfizer, Celgene, Medac, GSK, Roche, Chugai, Novartis, UCB, Janssen-Cilag, Astra-Zeneca, Lilly, Baxter, SOBI, Biogen, Actelion, Bayer Vital, Shire, Octapharm, Sanofi, Hexal, Mundipharm, Thermo Fisher. Consultant of: see above, Pia Moinzadeh: None declared, Nicolas Hunzelmann Speakers bureau: Actelion, Boehringer DOI: 10.1136/annrheumdis-2020-eular.3069 